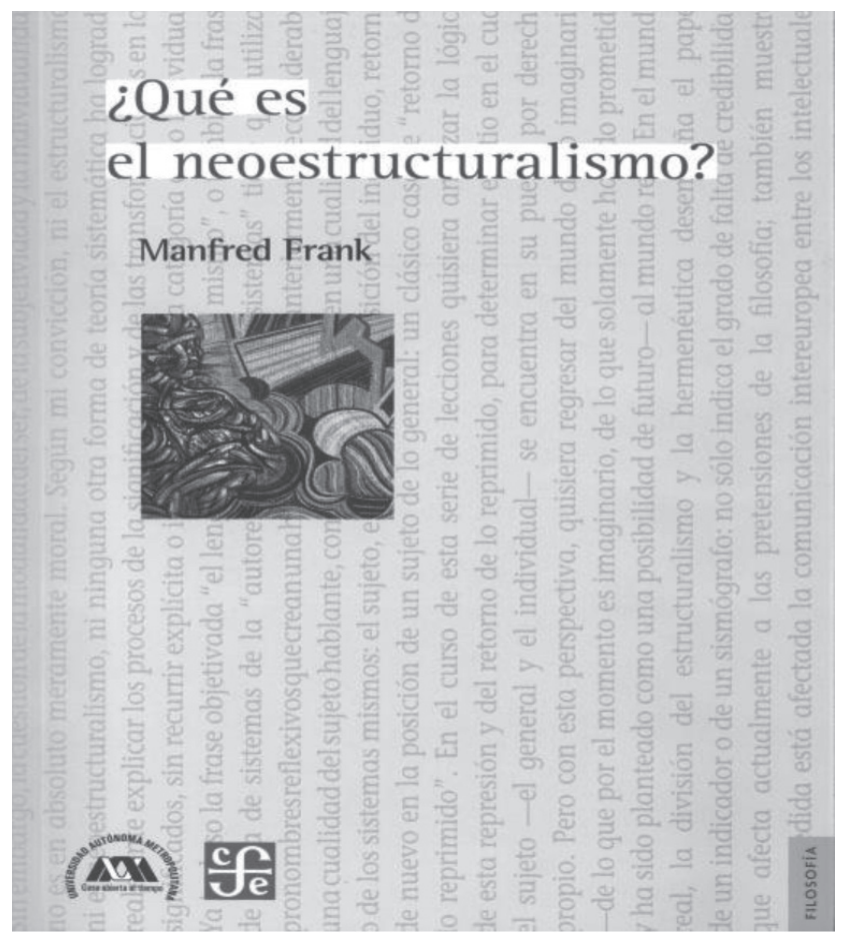

Reseña: ¿Qué es el neoestructuralismo? de Manfred Frank ${ }^{1}$

Frank, M. (2011). ¿Qué es el neoestructuralismo? México: Fondo de Cultura Económica. ISBN 978-607-477-539-6 (UAM); ISBN 978-607-16-0724-9

Fecha de recepción: 24 de abril de 2017

Fecha de aceptación: 24 de mayo de 2017

Forma de citar (APA): Garnica, N. (2018). Reseña: ¿Qué es el neoestructuralismo? de Manfred Frank. Revista Filosofía UIS, 17(1), doi: http://dx.doi.org/10.18273/ revfil.v17n1-2018016

Forma de citar (Harvard): Garnica, N. (2018). Reseña: ¿Quées el neoestructuralismo? de Manfred Frank. Revista Filosofía UIS, 17(1), 327-330.

Naím Garnica: argentino. Licenciado en Filosofía. Profesor en la Universidad Nacional de Catamarca, Departamento de Filosofía. Becario CONICET, Argentina.

Correo electrónico: naim_garnica@hotmail.com

${ }^{1}$ Reseña. 


\section{Reseña: ¿Qué es el neoestructuralismo? de Manfred Frank}

Publicada originalmente en alemán en 1983 y traducida al inglés en 1989 las lecciones dictadas por Manfred Frank ingresan al mundo de habla hispana después de casi treinta años de su presentación original. Esta obra constituye uno de los primeros intentos de la filosofía alemana contemporánea de acercarse al pensamiento francés producto de los años 60. A su vez, es una de las obras más reveladoras sobre la posición de Manfred Frank en torno a sus preocupaciones que aún hoy le acompañan, como asimismo, los supuestos desde los cuales las ha analizado. En términos generales, este texto muestra que su lectura reconstructiva - procedimiento denominado por Frank como hermenéutica constructiva- del neoestructuralismo se encuentra determinada por la tradición hermenéutica de Schleiermacher.

Respecto de su cuestionamiento a los conceptos de historia y subjetividad del neoestructuralismo los supuestos están orientados desde la filosofía del neoidealista Dieter Henrich quien le permite reconsiderar y cuestionar los conceptos de conciencia, autoconciencia y sujeto del neoestructuralismo. Por otra parte, Sartre, la lectura de Peter Szondi sobre el Romanticismo alemán y los propios románticos (Novalis, el joven Schelling y el joven Friedrich Schlegel) son un recurso de anticipación respecto de las "hipotéticas" novedades que el neoestructuralismo viene a develar. Lejos de considerarlo un pensamiento rupturista, Frank observa las distintas continuidades, analogías y paralelismos que los planteos de autores franceses tienen con tradiciones filosóficas anteriores, fundamentalmente, alemanas. Un lector atento de éstas 27 lecciones y un apéndice no puede dejarse llevar por la exposición del autor, aparentemente neutral y fiel a los textos de los autores en cuestión, pues perderá de vista las críticas de fondo al neoestructuralismo.

Aunque la organización del texto se encuentre orientada a informar, enseñar y difundir las obras de Foucault, Deleuze, Derrida, Althusser y Lacan, a su vez, constituyen la elaboración de una incipiente teoría del sujeto que luego se desarrollará en otros textos de Frank a partir de sus consideraciones sobre la individualidad. La apertura del texto intenta plantear un diálogo franco-alemán que en los años 80 se había desvanecido en las dos corrientes predominantes de la filosofía alemana: la Teoría Crítica y la Hermenéutica. Su intención es recordarle a la filosofía europea "su compromiso a favor de lo universal" (Frank, 2011, p. 11); una declaración desde la perspectiva hermenéutica que busca establecerse como norma. No obstante, su exposición no está ausente de críticas y objeciones. Dichas objeciones escoltan las 530 páginas del texto y su organización se puede distinguir en tres momentos o preguntas al neoestructuralismo: a) ¿Cómo se manifiesta con respecto al fenómeno de la historia? (Lecciones 6 a 12); b) icómo explica el fenómeno de la subjetividad? (Lecciones 12 a 24); y c) ¿de qué teoría 
de la formación de signos y de los efectos sensoriales dispone? (Lección 25 hasta el final).

Antes de llegar a estos interrogantes, Frank nos conduce por las fuentes del neoestructuralismo, revisando pacientemente a Saussure y Lévi-Strauss a los efectos de establecer rupturas y continuidades entre ambos pensamientos. A su juicio, el pensamiento elaborado por los filósofos franceses antes indicados se encuentra lejos de ser un corte definitivo con el estructuralismo clásico, algo que se ha repetido hasta el cansancio a los fines de resaltar su especificidad. De allí que Frank bautice a este movimiento con el prefijo neo- y no post- como habitualmente lo encontramos. Su diálogo interno con el estructuralismo clásico, a pesar de concebirse a sí mismo como un pensamiento post-metafísico y posterior al estructuralismo, es expuesto por las primeras lecciones.

Frank muestra hasta el final de sus lecciones de qué modo el objetivo del neoestructuralismo de quitarle la corona de rey de la filosofía al sujeto moderno no logra dar en el blanco. En primer lugar, debido a que Derrida, Foucault, Lacan y Deleuze no disponen de las armas necesarias para ese ataque, en gran medida por su desconocimiento de las teorías de la autoconciencia moderna. En segundo lugar, sus informantes para llevar a cabo una historia de la subjetividad (objeto de crítica del neoestructuralismo), están todavía más equivocados. Nietzsche, Heidegger y Wittgenstein como precursores de la teoría del sujeto del neoestructuralismo son explicados y refutados debido a su omisión en relación a teorías de la conciencia moderna. Básicamente, contar la historia de la subjetividad como un desarrollo de interpretaciones sobre el Ser como presencia, hasta llegar al oscurecimiento u olvido del mismo en la autoconciencia como presencia ante sí de la era moderna, constituye una falacia, además de ser "demasiado bella para ser verdad" (Frank, 2011, p. 289). Según Frank, es inexacto que corrientes como el idealismo y el romanticismo piensen a la autoconciencia como presencia ante sí. La teoría idealista-romántica parte del escepticismo de una instancia segura para el Yo, dicho fundamento no es inmediato ni tampoco presente, de modo tal que hace imposible un sistema del saber autoconsciente. Frank asevera que "les debemos la clara comprensión de la imposibilidad de pensar la familiaridad que la conciencia tiene consigo misma como una relación de reflexión [...] son de una calidad de la que no cae ni un reflejo sobre la obra de Derrida" (290). La filosofía romántica ha postulado desde Novalis a Schlegel que la conciencia no es productora de sí, expropiándole el derecho de autonomía y soberanía atribuida por el neoestructuralismo. Incluso, en Schelling por ejemplo, se utilizan conceptos como "Ser Inmemorial" para distinguir aquello que la conciencia no dispone. A partir de ello, la conciencia se muestra lanzada y desnuda, sin tener el poder de determinarse a sí misma. Frank no está convencido de que el sujeto sea identificado como agente natural de la razón universal. Tampoco coincide con la consideración neoestructuralista del sujeto moderno como voluntad de poder opresora, uniforme y hegemónica. Al contrario, Frank propone revisar la forma 
en la que el sujeto es entendido en los distintos sistemas filosóficos y, al mismo tiempo, investigar semánticamente sobre lo que se designa como sujeto.

La posición hermenéutica de Frank no está dispuesta a renunciar a que todo sentido, significante, significado, interpretación, no se refiera o esté, sugerida a una conciencia. Su explicación del neoestructuralismo convoca a defender a la conciencia que otorga sentido frente a la intención de disolverla. El autor mantiene la confianza en "que puede defender exitosamente su realidad del intento neoestructuralista de disolverla (o más bien: desaparecerla) en el hueco de la différance" (Frank, 2011, p. 315). Si el lector está interesado en entender los puntos cardinales de la teoría francesa se encontrará con lo que pretende, pero también con observaciones críticas de su recepción en el contexto alemán. Se puede observar de qué modo el postestructuralismo es sentado en el banquillo de acusados para ser incriminado de neoconservadurismo e irracionalismo reaccionario. Pese a que durante los años 70 la autoridad explicativa era la Teoría Crítica de orientación hegeliano-marxista y avanzada la década de los 80 la Teoría de la acción comunicativa orientada por Habermas emergía como la referencia filosófica, el respiro parecieran traerlo los aires convulsionados de la Francia postMayo del 68 en los nombres de Foucault, Derrida, Deleuze y Lacan.

Las lecciones de Frank son un intento de lectura crítica de estas corrientes desde la hermenéutica, pero también conservan el propósito de establecer un diálogo de aprendizaje con las corrientes francesas. En Francia las lecciones sobre el neoestructuralismo ayudaron a aumentar el rechazo a la filosofía alemana y, en Alemania, por su parte, permitió despertar el interés en el estudio de estas corrientes. En fin, ¿Qué es el neoestructuralismo? contribuye a valorar las posiciones de Frank en la filosofía contemporánea y su recepción de problemáticas filosóficas anteriores (el romanticismo, el idealismo alemán, el problema de la conciencia, el individuo, la hermenéutica) supuestamente superadas y agotadas. A su vez, adquiere relevancia en los contextos académicos donde la alta teoría francesa se ha vuelto incuestionable y dogmática. Las páginas de este libro tienen el poder de revisar esos supuestos, como asimismo, la eficacia crítica de sorprenderse ante las fuentes que construyen al neoestructuralismo.

\section{Referencias}

Frank, M. (2011). ¿Qué es el neoestructuralismo? México: Fondo de Cultura Económica. 